\title{
Result of closed interlocking intramedullary nail in tibial shaft fracture

\author{
AHSM Kamruzzaman1, S Islam2
}

\begin{abstract}
The management of tibial diaphyseal fractures has always held a particular interest for orthopedic surgeons. Not only they are relatively common but also they are often difficult to treat. This prospective study was carried out at Rangpur from April 2008 to November 2009. 34 patients were treated by closed interlocking intramedullary nail. Goal of this study was to find out a safe, effective management of fracture, early mobility of patient, functional joint motion and short stay in hospital. Routine follow up was carried out in 29 patients. In 24 cases, fracture (81.76\%) were united, 4 cases (13.79\%) needed dynamisation with autogenous bone grafting and 1 case devoloped non union. Study showed interlocking nailing in tibia provides early mobility of patients, reduces hospital stay and fracture unites without joint stiffness and less complication.
\end{abstract}

Bang Med J (Khulna) 2011; 44 : 15-17

\section{Introduction}

The tibia by its location is exposed to frequent injuries as one third of its surface is subcutaneous. Treatment of tibial fracture in adult is a challenge to Orthopedic surgeons due to poor soft tissue coverage and blood supply. Moreover compartment syndrome, neurovascular injury and infection might add to this burden. Later non union, delayed union and malunion may include.

The acceptable treatment goal for fracture tibia is union maintaining normal length, normal alignment without rotation, deformity, normal joint movement and reduced hospital stay. About 40 years ago charnley (1961) said, "we have still a long way to go before the best method of treating a fracture of the shaft of tibia can be stated with finality".1 Intramedullary nail (Lottes, Ender) has been used for a long time for fixation of tibia.2

As there are variations in treatment of tibial fracture, it is very difficult to manage all the cases by a single treatment method. Over last 50 years the management of tibial fracture has oscillated like a pendulum of a clock from non surgical treatment to surgical treatment. In the past, tibial shaft fracture were managed by immobilization in a plaster cast.3 Thereafter functional brace has been used commonly.4 The first use of an intramedullary rod is attributed by lambott in 1907.5 In 1974 a semi-rigid triflange intramedullary nail is introduced for closed nailing in tibia without reaming.6 But problems remain with comminuted fractures and the nail does not provide rotational stability and normal length. In 1960s and 1970s external fixation was most popular.7 The plating resulted in higher incidence of non Union, infection and fixation failure.8 The external fixation resulted in pintract infection and sometimes osteomyelitis of bone.9 Due to these problems a new technique close tibial interlock nailing was developed that minimize the chances of post operative infection,10 promotes early union, regain early activity 11 and reduce exposure and operative trauma.
Interlocking nail is an intramedullary nail that is fixed to the bone with screws at both ends. Close tibial interlocking nail is a procedure in which closed reduction of the fracture is done without opening the fracture site and then intramedullary interlocking nail is introduced at tibial tuberosity and fixed at both ends with screws. Close tibial interlock nailing was initially used without reaming but due to delayed union and non union the reamed interlocking was started. It provides the ability to control normal length, correction of angulations and rotation. In interlocking system, sophisticated equipment C-ARM is essential to locate and drill the distal screw site but which is not available at Rangpur. Instead that portable X-ray used in our study during operative procedure. Closed interlocking intramedullary nailing with the help of portable X-Ray was our prime challenge and we are able to cross that barrier last of all.

\section{Material and methods}

This prospective study was carried out at Rangpur Medical College hospital and private Clinics, Rangpur from April 2008 to November 2009. A total of 34 patients aged from 25 yrs. to 65 yrs. were selected according to inclusion and exclusion criteria.

Inclusion criteria : a) Closed diaphyseal fracture of tibia. b) Adults (after the closer of epiphysis) c) Location of fracture (fracture $7 \mathrm{~cm}$. below the knee joint and $4 \mathrm{~cm}$ above the ankle joint). d) Types of fracture (Orthopedic association classification type A and type B fracture. e) Duration of fracture less than 04 wks). Exclusion criteria : a) Open fracture, b) Pathological fracture.

After fitting in the inclusion criteria of the admitted patient thorough history was elucidated, complete physical examination performed and investigations carried out. 23 cases were recent $(0-$ 5 days) and rest 11 were old less than 04 wks. 5 patients were lost from subsequent follow up. So ultimate cases were 29. All the patients were counseled about their condition which necessitated an urgency of the surgical procedure they had to undergo. Informed consent was taken from all the Patients. Preoperative ceftriaxon (2gm) was given on induction and interlocking intramedullary nails (8-11 mm of diameter and 30 to $38 \mathrm{~cm}$. long) were used. Antibiotics were continued for 02 weeks. Patients 
were mobilized on first postopertive day. Knee and ankle exercises were started. Patients were allowed for touch weight bearing on first post operative day, half weight bearing after six weeks when callus was seen on X-Rays and full weight bearing after fracture heals. Stitches were removed on fourteenth post operative day. Patients were followed up for fortnight for first visit and then every four weeks for subsequent visits for total time period of about 30 weeks. In each visit the progress of healing of fracture site was examined clinically and radiologically.

\section{Results}

Total number of patient were 34 but 5 patients were lost to follow up and were excluded from study and only 29 patients were followed up for 30 weeks.

Age range was between 25 and 65 yrs. and average age was 35 yrs. Twenty four (70.59\%) were male and ten $(29.41 \%)$ were female patients. In $21(72.41 \%)$ patients there was right sided fracture and in 8 (27.59\%) left sided fracture had been recorded. Three $(10.34 \%)$ patients had fracture of upper third, 16 (55.17\%) of middle third and 10 (34.48\%) of the lower third of tibia. There were 15 (51.72\%) type A and $14(48.27 \%)$ type $\mathrm{B}$ fracture according to OTA classification.

\section{Table I}

Mechanism of injury (n=29)

Cause

Motor vehicle accident

Fall

Number of patients $24(82.76 \%)$ 05(17.24\%)

Twenty four (82.76\%) fracture were due to motor vehicle accident and 5 (17.24\%) were due to fall (Table I). The average time of healing was 18 weeks. 15 (51.72\%) fractures healed in l6wks, $8(27.6 \%)$ in 20 weeks, 5 (17.24\%) in $24 \mathrm{wks}$ and 1 (3.45\%) in 30 wks. time (Figire1).

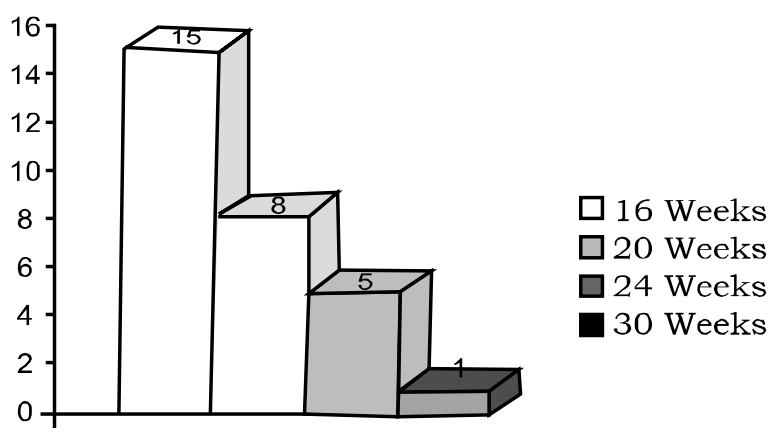

Figure 1 : Time of Healing

Knee pain was observed in 22 cases out of twenty nine patients 27 (93.10\%) had full range of ankle movements, 1 (3.45\%) had 10 degree restricted dorsiflexion while 1 (3.45\%) had 5 degree restricted eversion and inversion. The range of movement in knee joint was more affected. 26 (89.66\%) patient had full range of movements in knee, 2 (6.9\%) patients had 10 degree restricted knee flexion while 1 (3.45\%) patient had 20 degree restricted knee flexion.

Two patient developed blister on their leg after operation. These two patients were kept under observation for compartment syndrome and were found to have no signs of the syndrome. In $4(13.81 \%)$ patient there was delayed union that had been dynamized after three months. In another $1(3.45 \%)$ patient developed non union and needed bone grafting later on.

\section{Discussion}

Larsen et al studied 45 patients with reamed interlock nail in whom average time to fracture healing was 16.7 weeks and had two malunion while in our study healing time was 18 weeks with no malunion. Bonnevialle et al12 studied intramedullary nailing with reaming (Grosse-kempf nail) in 32 patients in whom only one case $(3.12 \%)$ developed deep infection while in our study there was no infection. He concluded that nailing with moderate reaming remains the preferred method of treatment of tibial diaphyseal fracture.13 Bonne vialle et al14 in another study pointed out that there was normal range of active movement in knee and ankle while 19 out of 38 (50\%) patient complained of pain at the site of the nail insertion while in our study knee pain was observed in 22 (75.90\%) cases. Steinberg15 and his colleagues studied 54 cases with diaphyseal fracture. They pointed out 11 (20.4\%) complications related to the nailing. 3 (5.55\%) deep infection, 2 (3.7\%) superficial infection, 2 bone shortening of 1 centimeter secondary to nail protrusion in the knee, 1 compartment syndrome, 1 fracture propagation, 1 distal malalignment and 1 delayed union. 15

Vaisto et al16 studied thirty six patients in whom 12 (33\%) patients were painless at knee and ankle and 24 (67\%) patients had anterior knee pain at follow-up while in our study knee pain was observed in 22 (75.90\%) patients. Vidyadharn et al17 studied the clinicoradiological out come of interlock nail in tibia in which he found that the average time of fracture healing was 20.1 weeks while in our study it was 18 weeks. He also pointed out that meticulous intramedullary nailing for tibial diaphyseal fracture has excellent clinico-radiological out come and is relatively safe.17 A study done in Turkey included 26 fractures that were treated by reamed intramedullary nailing. 18 The mean time to union has five months, while in our study it is 18 weeks. In their study they concluded that locked intramedullary nailing is more appropriate in comminuted fractures because of better preservation of periosteal circulation and thus lower complication rates.18 Court-Brown et al studied 25 patients with average union time of 15.4 weeks with no infection, malunion, non union or delayed union.

It is evident from above fact that closed interlocking intramedullary nailing is a safe and quite effective for treatment of tibial diaphyseal fracture.

\section{References}

1. Charnley, J.. The closed treatment of common fractures. 3rd ed., Edinburg: 1961;105.

2. Lottes, JO. Closed reduction, plate fixation and medullary nailing of fracture of both bones of the leg. J Bone Joint Surg (A). 1952; 34A : 861.

3. Elis $\mathrm{H}$. The speed of healing after fracture of tibial shaft. $\mathrm{J}$ Bone $\mathbf{J}$ Surg (Br) 1952; 40B ; 42-6.4.

4. Sarmiento A.A functional below-the-knee brace for tibial fractures. J Bone Joint Surg (Am) 1970; 52 : 295-311.

5. Kyle R.F.Biomechanics of intramedullary nailing fracture fixation. Orthopaedics 1985; $8:$ 1356-9.

6. Lottes J.O.Medullary nailing of the tibia with the triflange nail. Clin Orthop 1974; 105 : 253-60.

7. Myers SH, Spiegel D, Flynn JM. External fixation of high-energy tibia fractures. J Pediatr Orthop 2007; 27 : 537-9.

8. Janssen KW, Biert J, van Kampen A. Treatment of distal tibial fractures: Plate versus nail: A retrospective outcome analysis of matched pairs of patients. Int Orthop 2007; 31 : 709-14. 
9. Tornetta P 3rd, Bergman M, Watnik N, Berkowitz G, Steuer J. Treatment of grade III open tibial fractures. A prospective randomized comparison of external fixation and non reamed locked nailing. J Bone joint Surg 1994; 75 : 13-9.

10. Niedzwiedzki L. Use of reamed locked intramedullary nailing in the treatment of aseptic diaphyseal tibial non-union. Ortop Traumatol Rehabil 2007; 9 : 384-96.

11. Court-Brown CM, Keating IF, McQueen MM. Infection after intramedullary nailing of the tibia: incidence and protocol for management. J Bone Joint Surg [Br] 1992; 74 : 770-4.

12. Court-Brown CM. Will K Christie J, McQueen MM. Reamed or unreamed nailing for closed tibial fractures. A prospective study in Tscherne C1 fractures. J Bone Joint Surg [Br] 1996; $78: 580-3$.

13. Larsen LB, Madsen JE, Hoiness PR, Ovre S. Should insertion of intramedullary nails for tibial fractures be with or without reaming? A prospective, randomized study with 3.8 years' follow-up. J Orthop Trauma 2004; $18: 144-9$.
14. Bonnevialle P. Cariven P. Bonnevialle N, Mansat P, Martinel V, Verhaeghe L et al. Segmental tibia fractures: a critical retrospective analysis of 49 cases. Rev Chir Orthop Reparatrice Appar Mot 2003; 89 : 423- 32.

15. Bonnevialle P, Belumore Y, Foucras L, Hezard L, Mansat M. Tibial fracture with intact fibula treated by reamed nailing, Rev Chir Orthop Reparatrice Appar Mot 2000; 86 : 29-37.

16. Steinberg EL, Geller DS, Yacoubian SV, Shasha N, Dekel S. Lorich DG. Intramedullary fixation of tibial shaft fractures using an expandable nail: early results of 54 acute tibial shaft fractures. S Orthop Trauma 2006; 20 : 303- 9.

17. Vaisto 0, Toivanen J. Paakkala T. Jarvela T, Kannus P, Jarvinen M. Anterior knee pain after intramedullary nailing of a tibial shaft ftacture; An ultrasound study of the patellar tendons of 36 patients. Orthop Trauma 2005; 19 : 311-6.

18. Vidyadhara S. Sharath KR. Prospective study of the clinicoradiological outcome of interlocked nailing in proximal third tibial shaft fractures. Injury 2006; 37 : 536-42. 